\title{
Microstructural Integrity of Salvaged Penumbra after Mechanical Thrombectomy
}

\author{
(D) M.T. Berndt, (DC. Maegerlein, (D)T. Boeckh-Behrens, (DS. Wunderlich, (D). Zimmer, (DS. Wirth, (D)F.G. Mück, (DS. Mönch, \\ (D)B. Friedrich, and (D). Kaesmacher
}

\begin{abstract}
BACKGROUND AND PURPOSE: There are sparse data on the microstructural integrity of salvaged penumbral tissue after mechanical thrombectomy of large-vessel occlusions. The aim of the study was to analyze possible microstructural alteration in the penumbra and their association with clinical symptoms as well as angiographic reperfusion success in patients undergoing mechanical thrombectomy.
\end{abstract}

MATERIALS AND METHODS: All patients who underwent mechanical thrombectomy for large-vessel occlusions in the anterior circulation and who received an admission CT perfusion together with postinterventional DTIs were included $(n=65)$. Angiographic reperfusion success by means of modified Thrombolysis in Cerebral Infarction (mTICI) scale and clinical outcome were recorded. Microstructural integrity was assessed by DTI evaluating the mean diffusivity index within the salvaged gray matter of the former penumbra.

RESULTS: The mean diffusivity index was higher in completely recanalized patients $(\mathrm{mTICl} 3:-0.001 \pm 0.034$ versus mTICl $<3$ : $-0.030 \pm 0.055, P=.03$ ). There was a positive correlation between the mean diffusivity index and NIHSS score improvement $(r=0.49, P=.003)$ and the mean diffusivity index was associated with midterm functional outcome $(r=-0.37, P=.04)$ after adjustment for confounders. In mediation analysis, the mean diffusivity index and infarction growth mediated the association between reperfusion success and clinical outcomes.

CONCLUSIONS: The macroscopic salvaged penumbra included areas of microstructural integrity changes, most likely related to the initial hypoperfusion. These abnormalities were found early after mechanical thrombectomy, were dependent on angiographic results, and correlated with the clinical outcome. When confirmed, these findings prompt the evaluation of therapies for protection of the penumbral tissue integrity.

ABBREVIATIONS: IQR = interquartile range; LVO = large-vessel occlusion; MD = mean diffusivity; MT = mechanical thrombectomy; SD = standard deviation; $\mathrm{mTICI}=$ modified Thrombolysis in Cerebral Infarction; $\mathrm{mRS}=$ modified Rankin Scale; NIHSS = National Institutes of Health Stroke Scale

M echanical thrombectomy (MT) has emerged as the standard of care for patients who present with anterior circulation large-vessel occlusions (LVO). ${ }^{1-7}$ MT is associated with high reperfusion rates and reduces the final infarct volume as opposed to medical treatment alone. However, the benefit of MT may not be fully explained by a mere reduction of the final infarct volume. Previous analyses have suggested that microstructural alterations also occur in hypoperfused areas, which do not undergo final

Received July 10, 2019; accepted after revision October 24

From the Departments of Neuroradiology (M.T.B., C.M., T.B.-B., C.Z., S.M., B.F.), and Neurology (S.W.), Klinikum rechts der Isar, School of Medicine, Technical University of Munich, Munich, Germany; Department of Radiology (S.W., F.G.M.) Donauisar Hospital, Deggendorf, Germany; and Department of Neuroradiology (J.K.), Inselspital, University Hospital Bern, University Bern, Bern, Switzerland.

*B. Friedrich and J. Kaesmacher contributed equally to this work.

Work originated from Department of Neuroradiology, Klinikum rechts der Isar, School of Medicine, Technical University of Munich, Munich, Germany. infarction, as evidenced by conventional macrostructural DWI ("salvaged penumbra"). ${ }^{8-10}$ If microstructural changes of the salvaged penumbra occur after MT is currently unknown. The aim of this analysis was to assess the occurrence of microstructural changes in the salvaged gray matter in patients undergoing MT by using postinterventional DTI. Secondary aims included the assessment of a potential relationship between microstructural changes, angiographic reperfusion success, and clinical outcomes.

Please address correspondence to Maria Berndt, MD, Department of Neuroradiology, Klinikum rechts der Isar, School of Medicine, Technical University of Munich, Ismaninger Str. 22, 81675 Munich, Germany; e-mail: maria.berndt@tum.de.

Indicates article with supplemental on-line appendix.

http://dx.doi.org/10.3174/ajnr.A6364

AJNR Am J Neuroradiol 41:79-85 Jan 2020 www.ajnr.org 


\section{MATERIALS AND METHODS}

\section{Sample and Patient Description}

All patients included in a prospective stroke registry of a single comprehensive stroke center and treated with MT between April 2016 and December 2018 were reviewed. Four-hundred-thirtynine patients with ischemic stroke presented with an LVO of the anterior circulation (MCA or carotid-T). Patients were included if they had postinterventional MR imaging, including DTI and structural 3D T1WI $(n=192)$. Patients with motion artifacts $(n=20)$ or space-occupying malignant infarction were excluded $(n=7)$. From the remaining 165 patients, 65 patients received quality-sufficient $\mathrm{CT}$ perfusion imaging on admission. Prospectively collected baseline demographic, clinical, and interventional data were extracted from the registry. Boardcertified neurologists assessed NIHSS scores on admission and at the time of MR imaging acquisition. The functional outcome was evaluated by applying the modified Rankin Scale (mRS) 90 days after admission, either on a routinely scheduled clinical visit or by a structured telephone interview. This study was approved by the local ethics committee, and the need for patient consent was waived.

\section{Angiographic Data}

The modified Thrombolysis in Cerebral Infarction (mTICI) score $^{11}$ was determined by 2 experienced neuro-interventionalists in consensus (C.M., B.F.). Complete reperfusion was defined as mTICI 3. The time of groin puncture, time of reperfusion, and corresponding procedure times were extracted from the data base. The time elapsed between groin puncture to reperfusion is referred to as reperfusion time. If no successful recanalization was achieved ( $\mathrm{mTICI}<2 \mathrm{~b}$ ), then the control series after the last maneuver was used as the time point of procedure termination.

\section{Assessment of the Penumbra in Admission CT Imaging}

Standard nonhelical cerebral CT was performed on a 64-row CT scanner equipped with a $40-\mathrm{mm}$ detector (Brilliance 64 , Philips Healthcare, Best, the Netherlands). The scanner was calibrated weekly by air calibration and regularly by using phantom scans (CT calibration phantom; Mindways Software, Austin, Texas). Besides noncontrast images and CT angiography, a perfusion image was acquired by using the following parameters: $120 \mathrm{kV}, 400 \mathrm{mAs}$, with $5-\mathrm{mm}$ section thickness. A dual-head power injector (Medrad, Indianola, Pennsylvania) with an 18-gauge IV access was used for contrast injection. A delay of 5 seconds was applied after injecting $40 \mathrm{~mL}$ Imeron (400 mg I/mL Iomeron 350, iomeprol; Bracco, Milan, Italy) at a flow rate of $6 \mathrm{~mL} / \mathrm{s}$, followed by $90 \mathrm{~mL} \mathrm{NaCl}$. For postprocessing of the acquired CT perfusion images, RAPID (iSchemaView, Stanford, California) was used. This software is an operator-independent fully automated image processing and visualization tool, and allows on-line estimation of perfusion maps and mismatch masks. ${ }^{12}$ These maps were verified by a neuroradiologist (M.T.B.) with 3 years of experience. For assessing penumbral tissue, the individual hypoperfusion mask was extracted. With this, the hypoperfused tissue was estimated at threshold values of Tmax delay of $>6$ seconds and the admission infarct core was estimated at threshold values of relative $\mathrm{CBF}<30 \%{ }^{12-14}$

\section{Assessment of Microstructural Changes Within the Penumbra}

For analyses of microstructural tissue integrity within the above-identified penumbral tissue, an MR imaging examination was acquired in the acute poststroke phase, including DTI and structural T1WI. These data were postprocessed, coaligned with admission CT perfusion imaging, and analyzed with respect to microstructural tissue alterations within the salvaged penumbra by using the mean diffusivity (MD) index for gray matter. The salvaged penumbra was defined as formerly hypoperfused tissue in CT perfusion imaging, which, in the end, did not show visible infarction, which was semiautomatically segmented in MR imaging (Fig 1). A detailed methodologic description is found in the On-line Appendix.

\section{Statistical Analysis}

The mean value comparison of the MD index and infarction growth was performed by means of a 2-sample $t$-test for independent samples. Wilcoxon rank sum tests were used for comparison of the NIHSS scores and mRS values between the different reperfusion groups.

To test the association of the MD index and infarction growth with the NIHSS score (at the MR imaging date and the percentage improvement compared with admission) as well as with midterm functional outcome (mRS after 90 days), the following statistical procedures were applied. After performing linear regression to get residuals of the MD index/ infarction growth (corrected for age, sex, time between recanalization and MR imaging scan, reperfusion time, admission infarct core), the Spearman rank bivariate correlation was performed between residuals of the MD index/infarction growth and the NIHSS score at the time of MR imaging as well as percentage improvement of the NIHSS score between admission and time of MR imaging and mRS at 90 days. In a second analysis, new residuals of the MD index that additionally control for infarction growth were calculated and used for Spearman rank bivariate correlation analyses with clinical outcome parameters.

In a mediation model, reperfusion success, measured by the mTICI score and dichotomized into complete and incomplete, was entered as the causal variable; percentage improvement of the NIHSS score between admission and the time of MR imaging as the outcome variable; and infarction growth and the MD index as mediator variables. The analysis was corrected for age, sex, and the time between recanalization and MR imaging by calculating residuals of infarction growth and the MD index by using linear regression. Path coefficients were estimated by using unstandardized regression coefficients of multiple regression analyses. Statistical significance of the indirect pathway, which reflects the impact of mediation, was evaluated by using a nonparametric bootstrap approach with 10,000 replication samples to obtain a 95\% CI. ${ }^{15,16}$ All statistical analyses were performed by using SPSS Statistics, version 25 (IBM, Armonk, New York). 


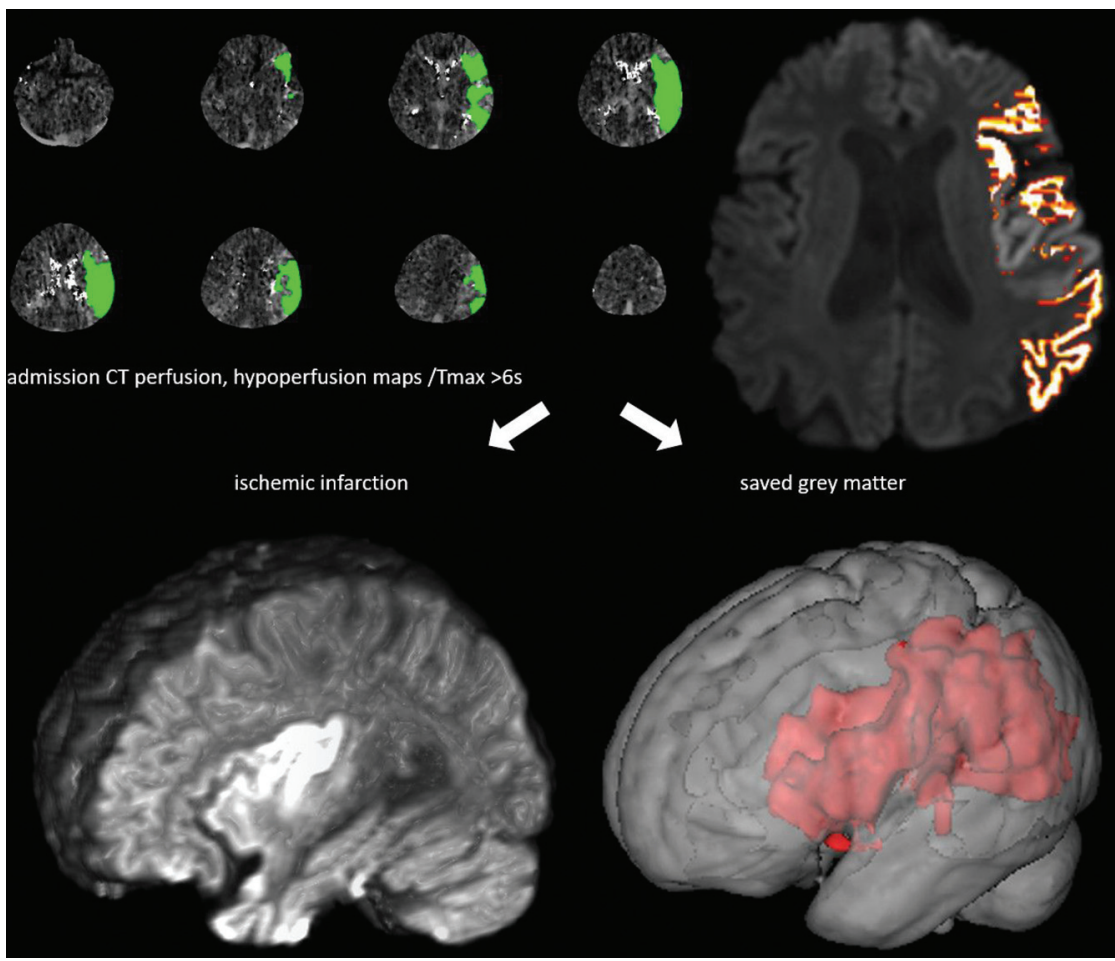

FIG 1. The tissue at risk (penumbra) in admission CT perfusion imaging (maps generated by RAPID software) was co-registered to MR imaging, including the DTI sequence, within 3 days after MT of acute occlusions of the anterior circulation. Penumbra was classified in ischemic infarction, segmented in DWI, and salvaged gray matter, which was further analyzed in respect to microstructural changes by calculation of the MD index in DTI (illustrations made by Mango [ric.uthscsa. edu/mango] and 3DSlicer [slicer.org]) (Reproduced with permission from Springer Nature https://doi.org/10.1007/s00062-019-00826-9).

Basic demographic, clinical, and interventional data as well as the volume of infarction, admission infarct core, and infarction growth of the final study cohort

\begin{tabular}{|c|c|}
\hline Patient Characteristics & $N=65$ \\
\hline Age, median (IQR), y & $75(63-83)$ \\
\hline Males/females, $n(\%)$ & $31(48) / 34(52)$ \\
\hline \multicolumn{2}{|l|}{ Interventional parameters (time), median (IQR) } \\
\hline Groin puncture to recanalization, min & $26(20-41)$ \\
\hline Symptom onset to recanalization, min & $199(144-310)$ \\
\hline No. maneuvers & $1(1-2.5)$ \\
\hline \multicolumn{2}{|l|}{ mTICI score, $n$} \\
\hline 0 & 2 \\
\hline $2 a$ & 2 \\
\hline $2 b$ & 22 \\
\hline 3 & 39 \\
\hline Additional IV thrombolysis, $n$ & 27 \\
\hline \multicolumn{2}{|l|}{ NIHSS score, median (IQR) } \\
\hline Pretreatment & $12(6-17)$ \\
\hline Time of MR imaging acquisition & $2(0-5)$ \\
\hline $\begin{array}{l}\text { Percentage improvement pretreatment to } \\
\text { time of MR imaging }\end{array}$ & $0.8(0.49-1)$ \\
\hline $\begin{array}{l}\text { Modified Rankin Scale (after } 90 \text { days) } \\
\quad(n=52)\end{array}$ & \\
\hline $0-2$ & 33 \\
\hline$>2$ & 19 \\
\hline $\begin{array}{l}\text { Time between recanalization and MR imaging } \\
\text { acquisition, median (IQR), days }\end{array}$ & $3(3-4)$ \\
\hline Volume of infarction, mean $\pm \mathrm{SD}, \mathrm{mL}$ & $28.8 \pm 48.8$ \\
\hline Admission infarct core, mean $\pm \mathrm{SD}, \mathrm{mL}$ & $14.3 \pm 24.9$ \\
\hline Infarction growth, mean $\pm \mathrm{SD}, \mathrm{mL}$ & $16.9 \pm 34.6$ \\
\hline
\end{tabular}

\section{RESULTS}

\section{Patient Characteristics}

Sixty-five patients were included (median age, 75 years; $52 \%$ female). Patients presented with severe symptoms (median [interquartile range $\{$ IQR $\}]$ NIHSS score, 12 [6-17]) and postinterventional MR imaging was scheduled at a median (IQR) of 3 days (3-4 days) after reperfusion. Most of the patients $(n=39 / 65,60 \%)$ had complete reperfusion (mTICI 3), whereas only 4 patients (6.2\%) were unsuccessfully recanalized (mTICI < 2b). Further details can be found in the Table.

\section{Microstructural Changes of the Salvaged Penumbra}

For the whole study cohort, the MD index of the salvaged penumbra showed mainly negative values (mean \pm standard deviation [SD], $-0.013 \pm$ 0.046). The MD index was higher in patients with complete reperfusion (mean $\pm \mathrm{SD},-0.001 \pm 0.034$ versus $-0.030 \pm 0.055, P=.03$ for mTICI 3 versus mTICI $0-2 b)$. A higher $\mathrm{MD}$ index means a smaller decrease of $\mathrm{MD}$ values within the salvaged gray matter in compari-

son with the contralateral side.

\section{Association of Micro- and Macrostructural Changes to the Clinical Outcome}

The following analyses showed the association of studied microstructural changes in the salvaged penumbra as well as infarction growth with clinical parameters: a significant negative correlation was found between the MD index and the NIHSS score at the time of MR imaging $(r=-0.43, P=.01)$ and mRS after 90 days $(r=-0.37, P=.04)$. A significant positive correlation was found between the MD index and percentage improvement of the NIHSS score between admission and the time of MR imaging ( $r=0.49, P=.003)$. A significant positive correlation was found between infarction growth and the NIHSS score at the time of MR imaging $(r=0.34, P=.05)$ and mRS after 90 days $(r=0.43$, $P=.02)$. A significant negative correlation was found between the infarction growth and the percentage improvement of NIHSS scores between admission and the time of MR imaging $(r=-0.409, P=.02)$.

After controlling for infarction growth, the MD index was negatively correlated with the NIHSS score at the time of MR imaging $(r=-0.28, P=.11)$ and $\mathrm{mRS}$ after 90 days $(r=-0.35$, $P=.05)$ and positively correlated with percentage improvement of the NIHSS score between admission and the time of MR imaging $(r=0.37, P=.03)$. All analyses were corrected for the abovementioned covariates under the precondition of complete 

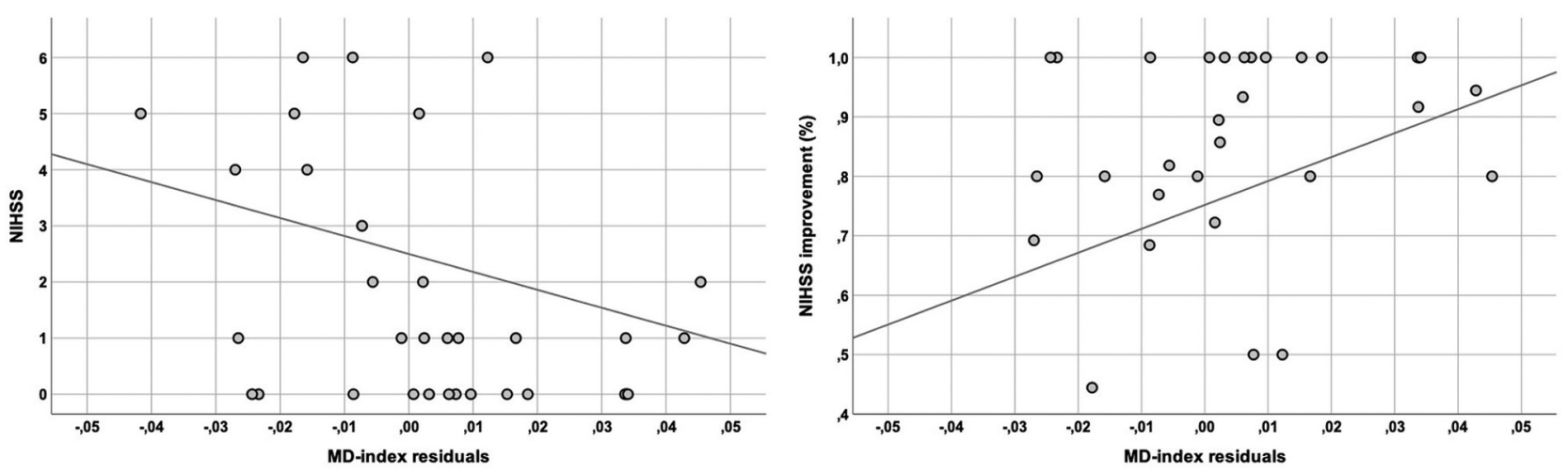

FIG 2. Graphs show the association of microstructural changes (measured by the MD index) with clinical outcome for all the patients who were completely recanalized. The MD index residuals (corrected for age, sex, time between recanalization and MR imaging, reperfusion time, admission infarct core) are negatively correlated to the NIHSS score at the time of MR imaging and positively correlated to percentage improvement of the NIHSS score between admission and the time of MR imaging.

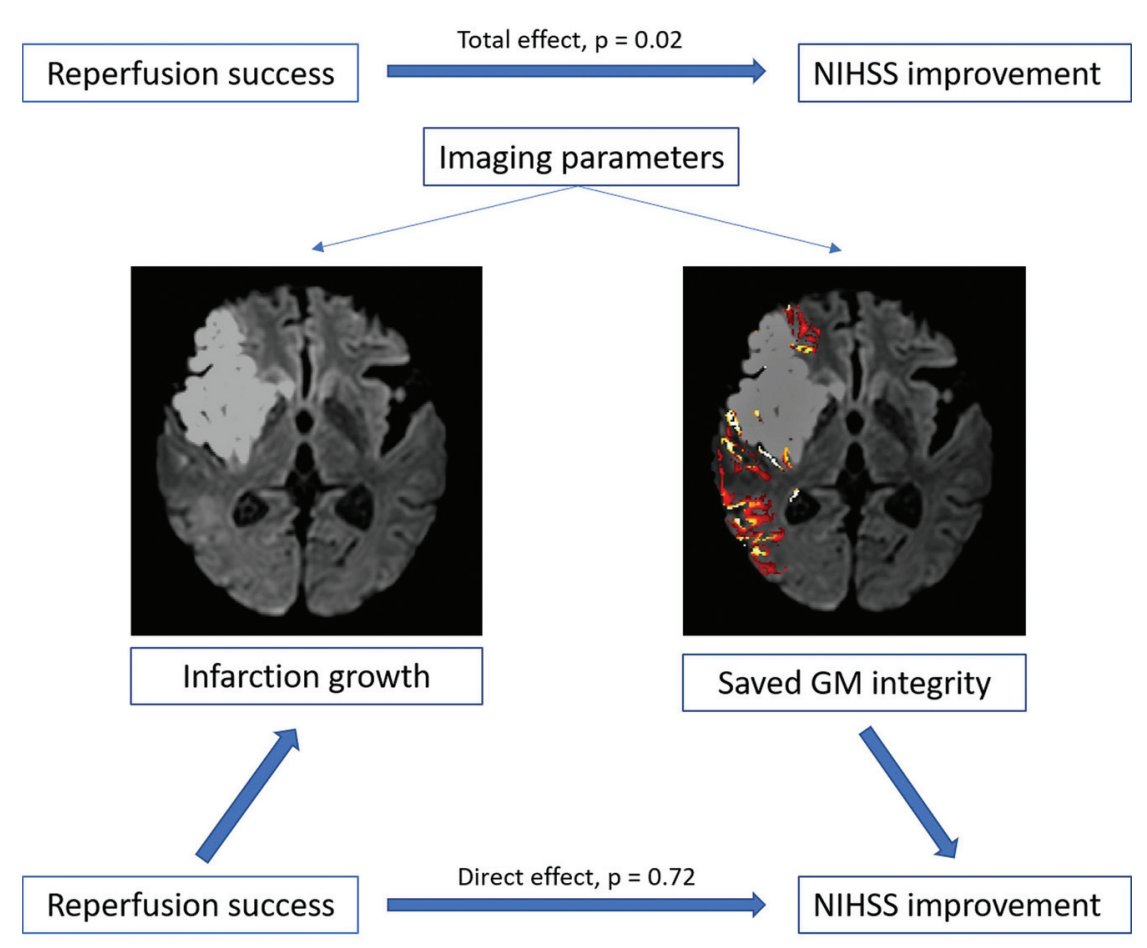

FIG 3. Imaging parameters, such as infarction growth and gray matter integrity of the saved tissue (measured by the MD index of the DTI within 3 days after MT of acute occlusions of the anterior circulation), significantly mediate the effect of reperfusion success (measured by $\mathrm{mTICI}$ ) on the clinical presentation (measured by percentage improvement of the NIHSS score); the covariates age, sex, and time between recanalization and MR imaging showed no significant influence in the analysis (Reproduced with permission from Springer Nature https://doi.org/10.1007/s00062-019-00826-9). median [IQR $\quad 0.47 \quad[0.24-0.87]$, $P=.02)$. In addition, an association between reperfusion success and imaging parameters, for example, the MD index, was found $(P=.03)$ (see the section Results: Microstructural Changes of the Salvaged Penumbra). The mean \pm SD volume of infarction growth also showed significantly different values, depending on the reperfusion success $(28.4 \pm 48.9 \mathrm{~mL}$ for incomplete and $9.24 \pm 17.0 \mathrm{~mL}$ for complete reperfusion, $P=.03$ ).

In a mediation analysis (Fig 3), the effect of reperfusion success (measured by mTICI) on the clinical presentation (measured by percentage improvement of the NIHSS score between admission and the time of MR imaging) (total effect $c=0.22$, $\mathrm{SE}=0.09, P=.02)$ was absent when controlling for imaging parameters such as infarction growth and the MD index (direct effect $c^{\prime}=0.03, \mathrm{SE}=$ $0.08, P=.72$ ); critically, the bootstrapped $95 \%$ CI for the indirect effect (ie, mediation: total - direct effect) was different from zero for the mediator variable infarction growth (95\% CI, 0.04-0.22) as well as for the MD reperfusion. The association between the MD index and the NIHSS score as well as NIHSS score improvement are shown in Fig 2.

\section{Impact of Tissue Integrity on the Relationship between Complete Reperfusion and Clinical Outcome}

The percentage improvement of the NIHSS scores between admission and the time of MR imaging differed significantly between the subgroups of complete reperfusion (mTICI 3: median [IQR] 0.9 [0.7-1]) and incomplete reperfusion (mTICI 0-2: index (95\% CI, 0.004-0.19) under consideration of the covariates, which indicated that both imaging parameters significantly mediated the relationship between reperfusion success and clinical improvement.

\section{DISCUSSION}

The present study shows that the macroscopic salvaged penumbra after MT includes areas of microstructural integrity changes related to the preceding hypoperfusion. The existence of 
microstructural integrity alterations was evaluated by using tissue integrity measurements by assessing diffusion parameters, such as the MD in a sample of 65 patients early after MT of an LVO of the anterior circulation. Compared with the contralateral side, a relative decrease of gray matter MD values within the salvaged penumbra was found. There was an explicit dependency on reperfusion success, which suggests that incomplete reperfusion results in further tissue abnormalities beyond macrostructural ischemia. Microstructural changes in the salvaged penumbra were further associated with neurologic and functional deficits, underlining their potential clinical importance.

The salvaged penumbra was identified by applying a co-registration process between DTIs in the acute poststroke phase and admission CT perfusion images, which visualize the tissue at risk. This penumbral tissue was assessed via RAPID software, which has been used in numerous studies. ${ }^{2,3,17,18}$ Penumbral tissue, which did not undergo final infarction in poststroke DTIs, was defined as the salvaged penumbra. Previous analyses have suggested that microstructural alterations also occur in the salvaged penumbra, ${ }^{8-10}$ which was affirmed in the present structural imaging study.

The MD alterations found in the acute poststroke phase with lowered values in the gray matter suggest cytotoxic-like processes with a decrease of the MD but on the microstructural, not the apparent level. ${ }^{19}$ As a result of this, assessing the cortical MD asymmetry compared with the contralateral nonaffected hemisphere has the potential to detect changes of the molecular diffusion rate, which can be affected by subtle integrity alterations. ${ }^{20}$ The asymmetry index was already used in several previous DTI studies, mostly in the context of FA (fractional anisotropy) calculations, and appeared as an accessible predictor variable. ${ }^{21-23} \mathrm{MD}$ loss within the salvaged penumbra that was temporarily undersupplied could either be a consequence of the primary ischemic processes when the tissue was at risk (eg, microembolization) or could arise out of ischemic reperfusion, which could exacerbate a primary ischemic injury. Results of studies with animal models found diffusion restriction early after stroke within the reversible penumbra similar to the findings in the present study in humans, and the studies discuss the phenomenon of reperfusion injury extensively. ${ }^{24}$

The observed "secondary deterioration" of diffusivity could be explained by a secondary energy failure after reperfusion, ${ }^{25,26}$ but the pathophysiological mechanism and processes of reperfusion injury are not yet conclusively clarified in humans. Existing pathophysiologic concepts explain the loss of diffusivity by a decline in extracellular water induced by a water shift from extracellular to intracellular space. This shift comes from cell depolarization because of a failure of adenosine triphosphate (ATP)-dependent pumps, which ATP levels are deteriorated by the over-release of toxic intermediates in reperfusion injury. ${ }^{24,27-29}$ Despite the underlying processes that cause such an observed integrity change in the salvaged penumbra, these alterations may be substantial with concern for technical, procedural, or clinical aspects.

A theoretic attempted explanation of microstructural changes of the salvaged penumbra would relate to clot fragmentation and distal microemboli, which occur within previously unaffected vascular territories as well as within the occlusion-dependent brain tissue during mechanical recanalization. Thus, the penumbral tissue would be less affected by lessening microembolic damage during recanalization. This explanation would fit the abovementioned theory of primary ischemic processes as a reason for MD loss caused by microembolization into the penumbral tissue. It encourages the usage of proximal flow arrest during mechanical recanalization, which was recently recommended by reporting improved procedural, angiographic, and clinical outcomes. ${ }^{30}$

The study results show a relationship between the MD values of the penumbral tissue and the clinical presentation at the time of MR imaging acquisition with a loss of MD correlated to a more significant concern measured by the NIHSS score. It is also associated with less percentage improvement of the NIHSS score between admission and the time of MR imaging and higher mRS after 90 days. Thus, MD loss has a negative association with the clinical presentation measured in the present study within the clinical workflow. Consequently, effort should be invested to minimize penumbral integrity changes within the therapeutic setting of an LVO.

A focus should be on gaining complete reperfusion because this is associated with a better clinical outcome as well as a reduced infarction growth and a better-preserved penumbral integrity as shown in the present study. By performing a mediation analysis on the relationship between reperfusion success and clinical outcome, imaging parameters of the acute poststroke phase, such as the infarction growth as well as the penumbral integrity, turned out to be significant mediators. By the disappearance of this known relationship, such imaging parameters gain importance because they can explain the impact of recanalization on clinical outcome, which again raises the meaningfulness of applying procedures with the aim of complete reperfusion and less macro- and microstructural tissue damage.

However, it is important to discuss that the observed microstructural integrity changes within the penumbra are measured at a single time within the acute poststroke phase. Reversibility of these abnormalities, which are well known even for macrostructural diffusion restrictions, was not proved. The results present microstructural diffusion restrictions within the penumbra, which is most probably based on the primary ischemic process and influenced by the therapeutic intervention (which was shown for reperfusion success). Follow-up imaging is required to examine reversibility, which was not the content of the present study. The first evidence of sustainable changes in terms of permanent damage could be derived from the existing association between microstructural penumbral changes and midterm functional outcome.

With regard to methodologic aspects, the analyses of tissue alterations were restricted to the gray matter and analyzing white matter integrity was not the content of the present study. By constructing the methodologies like this, the following aspects were considered: during ischemic processes, gray matter is more sensible to infarction, determined by the ischemic time, than white matter, which is secondarily dependent on the related gray matter in respect to processes like early disintegration. Thus, measuring the processes within the gray matter may reflect the ischemic processes more accurately and have an impact on further progressions, such as degeneration, which is important for the 
clinical outcome. However, studying white matter integrity by using fiber-tracking should be considered in further studies, which would, additionally, gain importance by creating a longitudinal approach.

\section{CONCLUSIONS}

The macroscopic salvaged penumbra included areas of microstructural integrity changes early after MT of an LVO in the anterior circulation. Penumbral microstructural integrity seemed to be dependent on recanalization success and was associated with clinical outcome. If confirmed, it harbors another rationale for further development of procedural processes of MT, with the aim for complete reperfusion, less ischemic macro- and microstructural injury, and, as a result of this, a better clinical outcome. The method used in this work enables the early consideration of the outcome on the microstructural level beyond the classic clinical scores.

Disclosures: Johannes Kaesmacher-UNRELATED: Grants/Grants Pending: SAMW Bangerter Foundation*; Travel/Accommodations/Meeting Expenses Unrelated to Activities Listed: Stryker.* Benjamin Friedrich-UNRELATED: Consultancy: Stryker, Medtronic; Grants/Grants Pending: iSchemaView. Stefan Wirth-UNRELATED: Board Membership: Past president of the European Society of Emergency Radiology, Comments: money paid to individual. The ESER Board Membership did not influence the submitted manuscript in any way; Travel/Accommodations/ Meeting Expenses Unrelated to Activities Listed: PPC meeting hotel costs, Comments: The European Society took over hotel costs that were related with a stay in Vienna to participate at the Programm Planning Committee for the ESR Congress 2020. Costs $<1000$ Euro. There is no connection to the submitted work. Claus Zimmer-UNRELATED: Board Membership: Scientific advisory boards for Philips and Bayer Schering; Grants/Grants Pending: Claus Zimmer disclosed no relevant relationships with regard to activities related to the present article. The institution has received research support and investigator fees for clinical studies from Biogen Idec, Quintiles, MSD Sharp and Dome, Boehringer Ingelheim, Inventive Health Clinical UK Ltd., Advance Cor, Brainsgate, Pfizer, Bayer-Schering, Novartis, Roche, Servier, Penumbra, WCT GmbH, Syngis, SSS International Clinical Research, PPD Germany GmbH, Worldwide Clinical Trials Ltd., Phenox, Covidien, Actelion, Medivation, Medtronic, Harrison Clinical Research, Concentric, Pharmtrace, Reverse Medical Corp., Premier Research Germany Ltd., Surpass Medical Ltd., GlaxoSmithKline, AXON Neuroscience, Bristol-Myers Squibb, Genentech, Acandis, EISAI, NeuroRx, Italfarmaco, Bioclinica, MIAC, and IXICO. No patents issued and pending*; Payment for Lectures, Including Service on Speakers Bureaus: Speaker honoraria from Bayer Schering and Philips. *Money paid to the institution.

\section{REFERENCES}

1. Goyal M, Demchuk AM, Menon BK, et al. Randomized assessment of rapid endovascular treatment of ischemic stroke. $N$ Engl J Med 2015;372:1019-30 CrossRef Medline

2. Saver JL, Goyal M, Bonafe A, et al. Stent-retriever thrombectomy after intravenous t-PA vs. t-PA alone in stroke. $N$ Engl $\mathrm{J} \mathrm{Med}$ 2015;372:2285-95 CrossRef Medline

3. Campbell BC, Mitchell PJ, Kleinig TJ, et al. Endovascular therapy for ischemic stroke with perfusion-imaging selection. $N$ Engl J Med 2015;372:1009-18 CrossRef Medline

4. Jovin TG, Chamorro A, Cobo E, et al. Thrombectomy within 8 hours after symptom onset in ischemic stroke. $N$ Engl J Med 2015; 372:2296-306 CrossRef Medline

5. Berkhemer OA, Fransen PS, Beumer D, et al. A randomized trial of intraarterial treatment for acute ischemic stroke. $N$ Engl J Med 2015;372:11-20 CrossRef Medline

6. Muir KW, Ford GA, Messow CM, et al. Endovascular therapy for acute ischaemic stroke: the Pragmatic Ischaemic Stroke Thrombectomy Evaluation (PISTE) randomised, controlled trial. J Neurol Neurosurg Psychiatry 2017;88:38-44 CrossRef Medline

7. Bracard S, Ducrocq X, Mas JL, et al. Mechanical thrombectomy after intravenous alteplase versus alteplase alone after stroke
(THRACE): a randomised controlled trial. Lancet Neurol 2016; 15:1138-47 CrossRef Medline

8. del Zoppo GJ, Sharp FR, Heiss WD, et al. Heterogeneity in the penumbra. J Cereb Blood Flow Metab 2011;31:1836-51 CrossRef Medline

9. Zhu LH, Zhang ZP, Wang FN, et al. Diffusion kurtosis imaging of microstructural changes in brain tissue affected by acute ischemic stroke in different locations. Neural Regen Res 2019;14:272-79 CrossRef Medline

10. Baron CA, Kate M, Gioia L, et al. Reduction of diffusion-weighted imaging contrast of acute ischemic stroke at short diffusion times. Stroke 2015;46:2136-41 CrossRef Medline

11. Zaidat OO, Yoo AJ, Khatri $P$, et al. Recommendations on angiographic revascularization grading standards for acute ischemic stroke: a consensus statement. Stroke 2013;44:2650-63 CrossRef Medline

12. Straka M, Albers GW, Bammer R. Real-time diffusion-perfusion mismatch analysis in acute stroke. J Magn Reson Imaging 2010; 32:1024-37 CrossRef Medline

13. Dehkharghani S, Bammer R, Straka M, et al. Performance and predictive value of a user-independent platform for CT perfusion analysis: threshold-derived automated systems outperform examiner-driven approaches in outcome prediction of acute ischemic stroke. AJNR Am J Neuroradiol 2015;36:1419-25 CrossRef Medline

14. Lansberg MG, Lee J, Christensen S, et al. RAPID automated patient selection for reperfusion therapy: a pooled analysis of the Echoplanar Imaging Thrombolytic Evaluation Trial (EPITHET) and the Diffusion and Perfusion Imaging Evaluation for Understanding Stroke Evolution (DEFUSE) Study. Stroke 2011;42:160814 CrossRef Medline

15. Hayes AF, Rockwood NJ. Regression-based statistical mediation and moderation analysis in clinical research: observations, recommendations, and implementation. Behav Res Ther 2017;98:39-57 CrossRef Medline

16. Preacher KJ, Hayes AF. SPSS and SAS procedures for estimating indirect effects in simple mediation models. Behav Res Methods Instrum Comput 2004;36:717-31 CrossRef Medline

17. Nogueira RG, Jadhav AP, Haussen DC, et al. Thrombectomy 6 to 24 hours after stroke with a mismatch between deficit and infarct. $N$ Engl J Med 2018;378:11-21 CrossRef Medline

18. Albers GW, Marks MP, Kemp S, et al. Thrombectomy for stroke at 6 to 16 hours with selection by perfusion imaging. $N$ Engl J Med 2018;378:708-18 CrossRef Medline

19. van Gelderen P, de Vleeschouwer MH, DesPres D, et al. Water diffusion and acute stroke. Magn Reson Med 1994;31:154-63 CrossRef Medline

20. Alexander AL, Lee JE, Lazar M, et al. Diffusion tensor imaging of the brain. Neurotherapeutics 2007;4:316-29 CrossRef Medline

21. Doughty C, Wang J, Feng W, et al. Detection and predictive value of fractional anisotropy changes of the corticospinal tract in the acute phase of a stroke. Stroke 2016;47:1520-26 CrossRef Medline

22. Puig J, Blasco G, Schlaug G, et al. Diffusion tensor imaging as a prognostic biomarker for motor recovery and rehabilitation after stroke. Neuroradiology 2017;59:343-51 CrossRef Medline

23. Stinear CM, Barber PA, Petoe $M$, et al. The PREP algorithm predicts potential for upper limb recovery after stroke. Brain 2012;135: 2527-35 CrossRef Medline

24. Guo J, Zheng HB, Duan JC, et al. Diffusion tensor MRI for the assessment of cerebral ischemia/reperfusion injury in the penumbra of non-human primate stroke model. Neurol Res 2011;33:10812 CrossRef Medline

25. Olah L, Wecker S, Hoehn M. Relation of apparent diffusion coefficient changes and metabolic disturbances after 1 hour of focal cerebral ischemia and at different reperfusion phases in rats. J Cereb Blood Flow Metab 2001;21:430-39 CrossRef Medline

26. Olah L, Wecker S, Hoehn M. Secondary deterioration of apparent diffusion coefficient after 1-hour transient focal cerebral ischemia in rats. J Cereb Blood Flow Metab 2000;20:1474-82 CrossRef Medline

27. Harris NG, Zilkha E, Houseman J, et al. The relationship between the apparent diffusion coefficient measured by 
magnetic resonance imaging, anoxic depolarization, and glutamate efflux during experimental cerebral ischemia. J Cereb Blood Flow Metab 2000;20:28-36 CrossRef Medline

28. Wei J, Quast MJ. Effect of nitric oxide synthase inhibitor on a hyperglycemic rat model of reversible focal ischemia: detection of excitatory amino acids release and hydroxyl radical formation. Brain Res 1998;791:146-56 CrossRef Medline
29. Rother J, de Crespigny AJ, D'Arceuil H, et al. Recovery of apparent diffusion coefficient after ischemia-induced spreading depression relates to cerebral perfusion gradient. Stroke 1996;27:980-86; discussion 986-87 CrossRef Medline

30. Brinjikji W, Starke RM, Murad MH, et al. Impact of balloon guide catheter on technical and clinical outcomes: a systematic review and meta-analysis. J Neurointerv Surg 2018;10:335-39 CrossRef Medline 